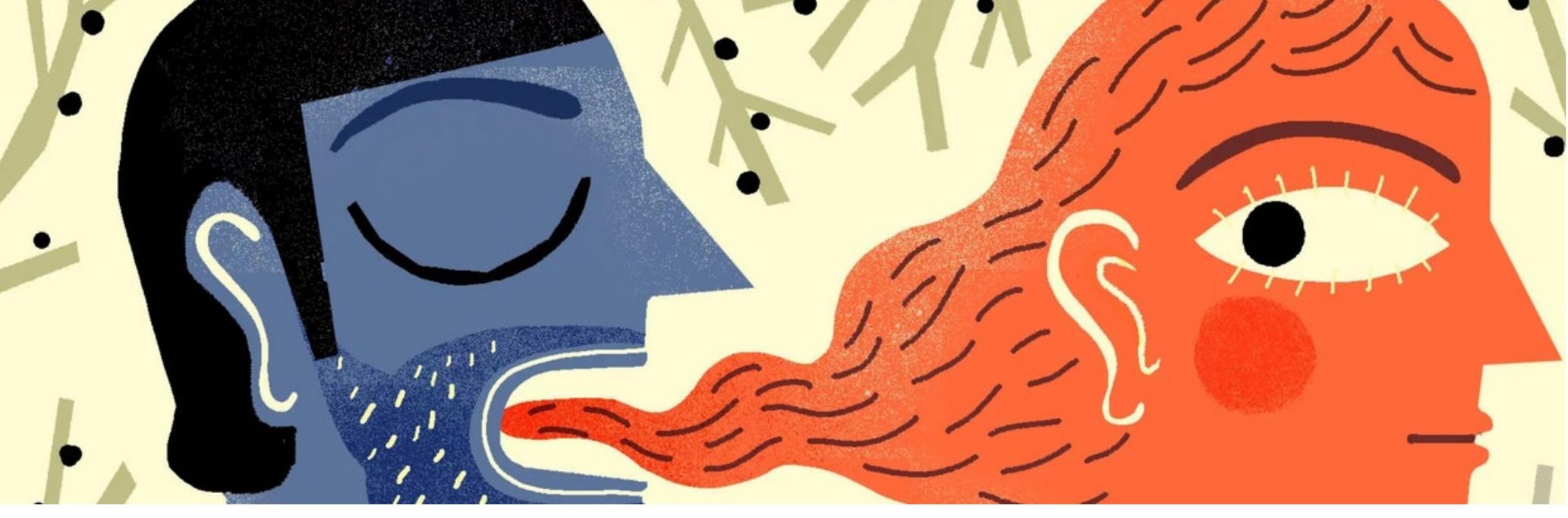

\title{
La lengua degenerada
}

\author{
Authors: Sol Minoldo, Juan Cruz Balian \\ Submitted: \\ Published: \\ Volume: \\ 29. March 2020 \\ Issue: \\ Affiliation: \\ Languages: \\ Keywords: \\ Categories: \\ 31. March 2020 \\ 7 \\ 2 \\ El Gato y La Caja Journal, Argentina, Buenos Aires \\ Spanish, Castilian \\ the degenerated language, lengua y lenguaje, grammar, el gato $y$ \\ la caja, journal project. \\ DOI: $\quad$ 10.17160/josha.7.2.651 \\ Humanities, Social Sciences and Law
}

Abstract:

Languages that attribute a grammatical gender to objects might induce a biased effect on how these objects are perceived. In a famous study by Lera Boroditsky, a list of 24 reverse-gendered nouns was prepared in Spanish and German. In each language, half of them were feminine and half masculine. Native Spanish and German speakers were shown the nouns, written in English, and asked about the first three adjectives that came to their minds. For instance, the word key is masculine in German. German speakers described keys as hard, heavy, metallic, and useful. In contrast, Spanish speakers described them as golden, small, adorable, shiny, and tiny. Conversely, the word bridge is feminine in German, and German speakers described bridges as beautiful, elegant, fragile, pretty, quiet, slender. Spanish speakers said that they were big, dangerous, strong, resistant, imposing, and long. In the most impactful article from El Gato $y$ La Caja community so far, Sol Minoldo and Juan Cruz Balián discuss the evidence supporting this concept and how this scenario aggravates inequities, as well as some of the available alternatives to overcome this situation.

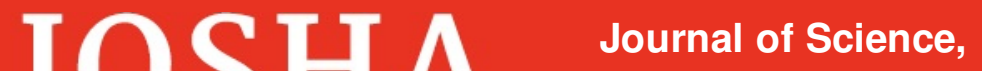 Humanities and Arts}




\title{
La lengua degenerada
}

\section{By Sol Minoldo \& Juan Cruz Balian}

\author{
Ilustradora: Mariana Ruiz Johnson \\ Fecha de publicación previa: 4/6/2018 \\ Extracto: ¿Tiene sentido hablar con lenguaje inclusivo? ¿Afecta nuestra percepción de \\ la realidad? \\ Link a la nota original: https://elgatoylacaja.com.ar/la-lengua-degenerada/
}

\begin{abstract}
Van dos peces jóvenes nadando juntos y sucede que se encuentran con un pez más viejo que viene en sentido contrario. El pez viejo los saluda con la cabeza y dice: "Buenos días, chicos, ¿cómo está el agua?”. Los dos peces jóvenes nadan un poco más y entonces uno mira al otro y dice: “¿Qué demonios es el agua?”

David Foster Wallace - This is Water
\end{abstract}

Cuando el escritor David Foster Wallace dio un discurso frente a los egresados de la Kenyon College comenzó contando esta historia de los peces. Su intención era simplemente recordarle al auditorio que todos vivimos en una realidad que, a fuerza de rodearnos, a la larga termina volviéndose invisible. Y que sólo la percibimos cuando se convierte en algo disruptivo, en un estorbo en nuestro camino: el conductor que nos cruza el auto en la esquina, el empleado que exige otro trámite para completar una solicitud, la palabra mal escrita: sapatilla, uevo, todxs. Mientras tanto, las cosas de las que más seguros solemos estar terminan demostrando ser aquellas sobre las que más nos equivocamos. Por ejemplo, el castellano: Todos los que nacimos y fuimos criados en el mundo hispanohablante tenemos, rápido y pronto, certezas sobre cómo funciona el castellano porque es la lengua que aprendimos intensamente durante nuestros primeros años de vida. Y en algún punto no nos equivocamos. Incluso si nos preguntasen qué es el castellano podríamos responder en un parpadeo: "es nuestra lengua materna". Pero esa respuesta no estaría dando cuenta de la verdadera naturaleza del asunto, porque en definitiva: ¿Qué demonios es la lengua? 


\section{Eso, ¿qué demonios es la lengua?}

Tal como el agua de los peces, la lengua es un poco todo. Mejor dicho, en todo está la lengua, dado que, una vez que la adquirimos, nunca más dejamos de usarla para pensar el mundo que nos rodea. Sin embargo, si tenemos que elegir una entre muchas definiciones, diremos que la lengua es un fenómeno social. Ocurre siempre con relación a un 'otro', a una comunidad con la que establecemos convenciones respecto a qué significan las palabras y cómo significan esas palabras. En este sentido, vale decir que nos pertenece a todos los que la hablamos. Y, en el caso de la lengua castellana, a la Real Academia Española (RAE).

¡Momento! ¿Por qué a la Real Academia Española? No parece muy lógico que la segunda lengua más hablada del globo (después del chino y antes del inglés) sea tan celosamente protegida por unos pocos señores enfurruñados. Pero menos sentido tiene cuando uno piensa que estos señores a veces se paran como caballeros templarios protegiendo algo que nadie, absolutamente nadie, está atacando.

Ah, ¿cómo? ¿Nuestros jóvenes no son como los peces descuidados y rebeldes? ¿No van por la vida con una promiscuidad lingüística escandalosa, escribiendo ke, komo, xq o todes? Sí, muchos sí. Los lectores se preguntarán cómo puede ser que permitamos semejante atropello. Resulta que la lengua no es una foto, es una película en movimiento. Y la Real Academia Española no dirige la película, sólo la filma. A eso llamamos 'gramática descriptiva', que es el trabajo de delimitar un objeto de estudio (en este caso lingüístico) y dar cuenta de cómo ocurre más allá de las normas. Por eso, cuando un uso se aleja de lo que indican los manuales de la escuela, si es llevado a cabo por suficiente cantidad de personas y se hace lugar en determinados espacios, la RAE acaba incorporándolo al diccionario. Ese es su trabajo descriptivo. Luego informa al público y ahí todos horrorizados ponemos el grito en el cielo porque cómo van a admitir 'la calor' si es obvio, requete obvio, que el calor es masculino. Es EL calor.

¿Esto significa que podamos hacer lo que se nos antoja con la lengua? No. Hay cambios que el sistema simplemente no tolera. Uno puede comprarse todas las témperas del mundo y mezclarlas a su placer, pero no puede imaginar un nuevo color. Algunas partes de la lengua funcionan de la misma manera: por ejemplo, no es posible pensar el castellano sin categoría de sujeto (ese que en la escuela había que marcar separado del predicado y cuando no estaba se le ponía 'tácito' al costado de la oración). ¿Es culpa de la Real Academia 
que no nos deja? No, esta vez la pobre no hizo nada, es el sistema mismo del castellano el que no nos deja. Es simplemente imposible.

Pero entonces, si podemos usar la lengua como queramos e igual no se va a romper, ¿por qué hace falta tomarse el trabajo de formular normas y leyes? La gramática que no es descriptiva, la que se encarga de definir qué está bien y qué está mal, se llama gramática normativa y existe por una razón: las normas son necesarias para poder analizar una lengua, sistematizarla y enseñarla mejor a las siguientes generaciones.

Lo importante en este punto es comprender que el castellano no puede ser atacado, o que en todo caso sabe defenderse solo (se dobla y se adapta como el junco, pequeño saltamontes) porque está en permanente movimiento. Cada generación cree que la lengua de sus padres es pura y prístina mientras que la de sus hijos es una versión degenerada de aquella. Pero antes de hablar castellano rioplatense hablábamos otra variante del castellano moderno. $Y$ antes de eso, hablábamos el castellano de Cervantes, y antes de eso las lenguas romances que fermentaron con la disolución del Imperio Romano, y antes de eso latín vulgar y antes del latín vulgar pululaban las lenguas indoeuropeas y antes de eso vaya uno a saber qué. Lo único que podemos saber a ciencia cierta es que la versión más pura, prístina y primigenia de cualquier lengua son unos gruñidos apenas articulados en el fondo de una caverna.

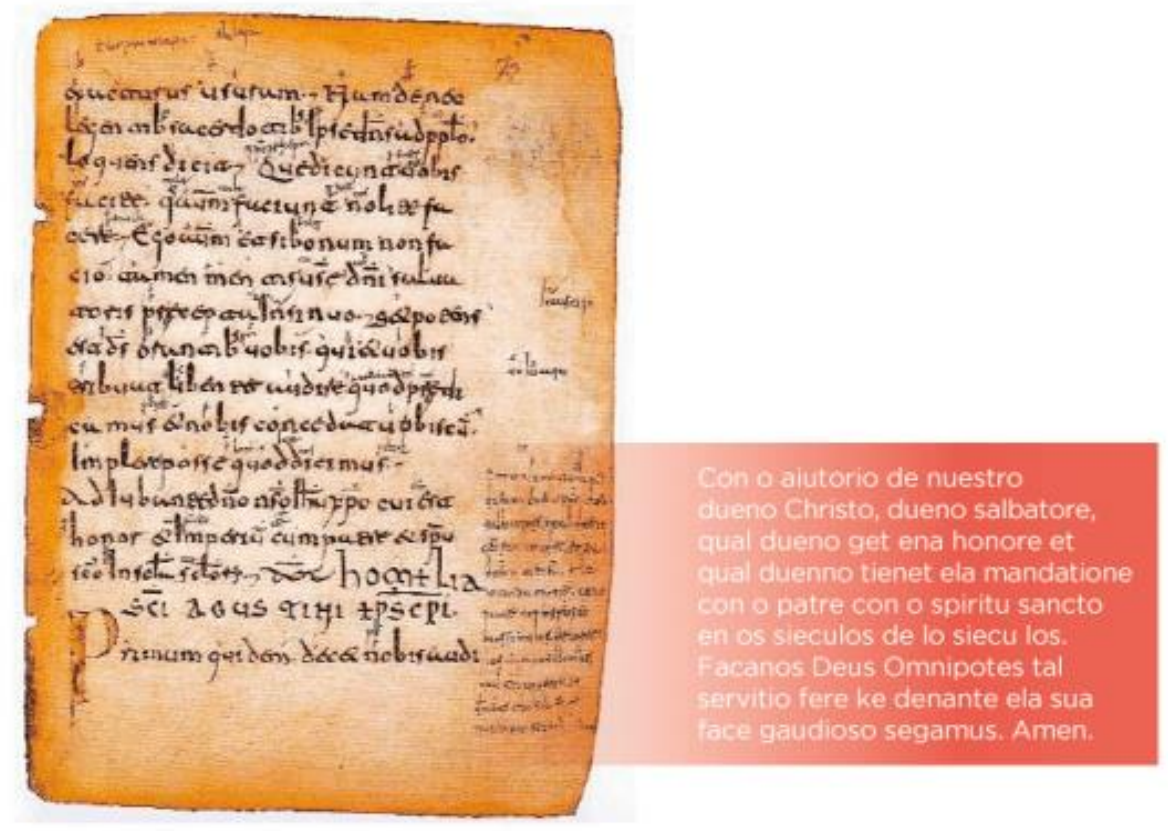

Las Glosas Emilianenses son uno de los registros más antiguos que tenemos del castellano. 
X u XI, para clarificar algún pasaje. Como se ve al costado, gracias a la glosa ahora el pasaje quedó clarito clarito.

Sirva como ejemplo la siguiente curiosidad: los españoles que llegaron a América durante la Conquista todavía utilizaban el voseo en sus dos vertientes: como forma reverencial y de confianza. Decían "Vuestra Majestad” o decían, por ejemplo, “¿Desto vos mesmo quiero que seáis el testigo, pues mi pura verdad os hace a vos ser falso y mentiroso?" (porque aguante citar el Quijote). Ese 'vos' arraigó en América, en parte a través de la literatura y en parte porque los españoles lo usaban reverencialmente entre ellos como modo de diferenciarse de los nativos. El tiempo pasó y hoy millones de personas lo usamos sin ningún tipo de reverencia ni distinción de clase, sin embargo, el voseo comenzó a desprestigiarse en el siglo XVI en la mismísma España, donde el castellano se decantó por el 'tú' sin que a nadie se espantara por eso. Lo cual demuestra que la lengua está en permanente cambio, pero ocurre tan lentamente que nos genera la sensación de permanecer detenida. Indignarse por ello sería como si los pececitos de la historia de Foster Wallace se indignasen porque el agua, que hasta recién ni sabían que existía, los está mojando.

Ahora bien, si llegado este punto los lectores de esta nota han aceptado las nociones básicas sobre el funcionamiento de la mismísima lengua que están leyendo, es momento de confesar que ha sido todo parte de una estratagema introductoria. Es hora de cruzar al otro lado del espejo y hablar de un tema un poco más controversial: el lenguaje inclusivo.

Bienvenides a la verdadera nota, estimades lecteres.

\section{Las formas del agua}

Una de las capacidades más poderosas de cualquier lengua es la capacidad de nombrar. Poner nombres, categorizar, implica ordenar y dividir. Y desde que nacemos (incluso antes), las personas somos divididas en varones y mujeres. Nos nombran en femenino o masculino, se refieren a nosotres utilizando todos los adjetivos en un determinado género. Muchísimo antes de que nuestro cuerpo tenga cualquier tipo de posibilidad de asumir un rol reproductivo, aprendemos que es diferente ser varón o mujer, y nos identificamos con los unos o las otras. Los nenes no lloran, las nenas no juegan a lo bestia ensuciándose todas. Para cuando podemos responder 'qué queremos ser cuando seamos grandes', nuestras preferencias, auto proyecciones y deseos ya tienen una enorme carga de los esquemas simbólicos que nos rodean. 
A esa inmensa construcción social, que se erige sobre la manera en que la sociedad da importancia a ciertos rasgos biológicos (en este caso relacionados con los órganos sexuales y reproductivos), es a lo que refiere el concepto de 'género'. Lo que los estudios sobre el tema han teorizado y documentado es que la división de géneros no es una división neutral, sin jerarquías: por el contrario, las diferentes características y los diferentes mandatos que se atribuyen a una persona según su género devienen, a su vez, en desigualdades que giran, spoiler alert, en torno a una predominancia de los individuos masculinos.

Haber identificado que esas desigualdades tienen su correlato en el modo en el que hablamos es lo que motivó, unas cuantas décadas atrás, que se plantee desde el feminismo y desde algunos ámbitos académicos y oficiales la importancia de revisar el uso del lenguaje sexista. ¿Qué es el lenguaje sexista? Es nombrar ciertos roles y trabajos sólo en masculino; referirse a la persona genérica como 'el hombre' o identificar lo 'masculino' con la humanidad; usar las formas masculinas para referirse a ellos pero también para referirse a todes, dejando las formas femeninas sólo para ellas; nombrar a las mujeres (cuando se las nombra) siempre en segundo lugar.

Las indeseables consecuencias de esta desigualdad lingüística se traducen en lo que el sociólogo Pierre Bourdieu define como 'violencia simbólica', y esto nos sirve para comprender uno de los mecanismos que perpetúan la relación de dominación masculina.

La violencia simbólica tiene que ver con que nos pensemos a nosotres mismes, al mundo y nuestra relación con él, con categorías de pensamiento que, de algún modo, nos son impuestas, y que coinciden con las categorías desde las que le dominader define y enuncia la realidad. Se produce a través de los caminos simbólicos de la comunicación y del conocimiento, y consigue que la dominación sea naturalizada. Su poder reside precisamente en que es 'invisible'. De nuevo, como el agua, se vuelve parte de la realidad y ni nos damos cuenta que está ahí.

Pero la violencia simbólica de la que habla Bourdieu no constituye, como a veces se malinterpreta, una dimensión opuesta a la violencia física, 'real' y efectiva. Es, en realidad, un componente fundamental para la reproducción de un sistema de dominio donde les dominades no disponen de otro instrumento de conocimiento que aquel que comparten con les dominaderes, tanto para percibir la dominación como para imaginarse a sí mismes. $\mathrm{O}$, mejor dicho, para imaginar la relación que tienen con les dominaderes. 
Revertir esto requiere algo así como una 'subversión simbólica', que invierta las categorías de percepción y de apreciación de modo tal que les dominades, en lugar de seguir empleando las categorías de les dominaderes, propongan nuevas categorías de percepción y de apreciación para nombrar y clasificar la realidad. Es decir, proponer una nueva representación de la realidad en la cual existir.

\section{Existir a través del lenguaje}

Pero la sociología no está sola en esto: desde el palo de la lingüística, en los años '50 vio la luz una teoría que proponía que la lengua 'determinaba' nuestra manera de entender y construir el mundo o, por lo menor, modelaba nuestros pensamientos y acciones. Era la famosa teoría Sapir-Whorf.

Durante mucho tiempo, la idea de que la lengua que hablamos podía moldear el pensamiento fue considerada en el mejor de los casos incomprobable y, con más frecuencia, sencillamente incorrecta. Pero lo cierto es que la discusión se mantenía principalmente en el plano de la reflexión abstracta y teórica. Con la llegada de nuestro siglo resurgieron las investigaciones acerca de la relatividad lingüística y, de la mano, comenzamos a disponer de evidencias acerca de los efectos de la lengua en el pensamiento. Diferentes investigaciones recolectaron datos alrededor del mundo y encontraron que las personas que hablan diferentes lenguas también piensan de diferente manera, y que incluso las cuestiones gramaticales pueden afectar profundamente cómo vemos el mundo.

\section{Todo muy lindo, ¿y la evidencia?}

Para empezar, Daniel Cassasanto y su equipo encontraron evidencia, como resultado de 3 experimentos, de que las metáforas espaciales (las del tipo 'la espera se hizo muy larga') en nuestra lengua nativa pueden influenciar profundamente el modo en que representamos mentalmente el tiempo. Y que la lengua puede moldear incluso procesos mentales 'primitivos' como la estimación de duraciones breves.

Y no fueron les úniques, otros equipos, como este, este, este, este y este, encontraron que la lengua con la que hablamos tiene mucho que ver con la forma en que pensamos en el espacio, el tiempo y el movimiento. Por otro lado, un estudio de Jonathan Winawer y su equipo aporta que las diferencias lingüísticas también provocan diferencias al momento de distinguir colores: es más fácil para une hablante distinguir un color (de otro) cuando existe una palabra en su idioma para nombrar ese color que cuando no existe esa palabra. Quien quiera celeste, que lo pronuncie. 

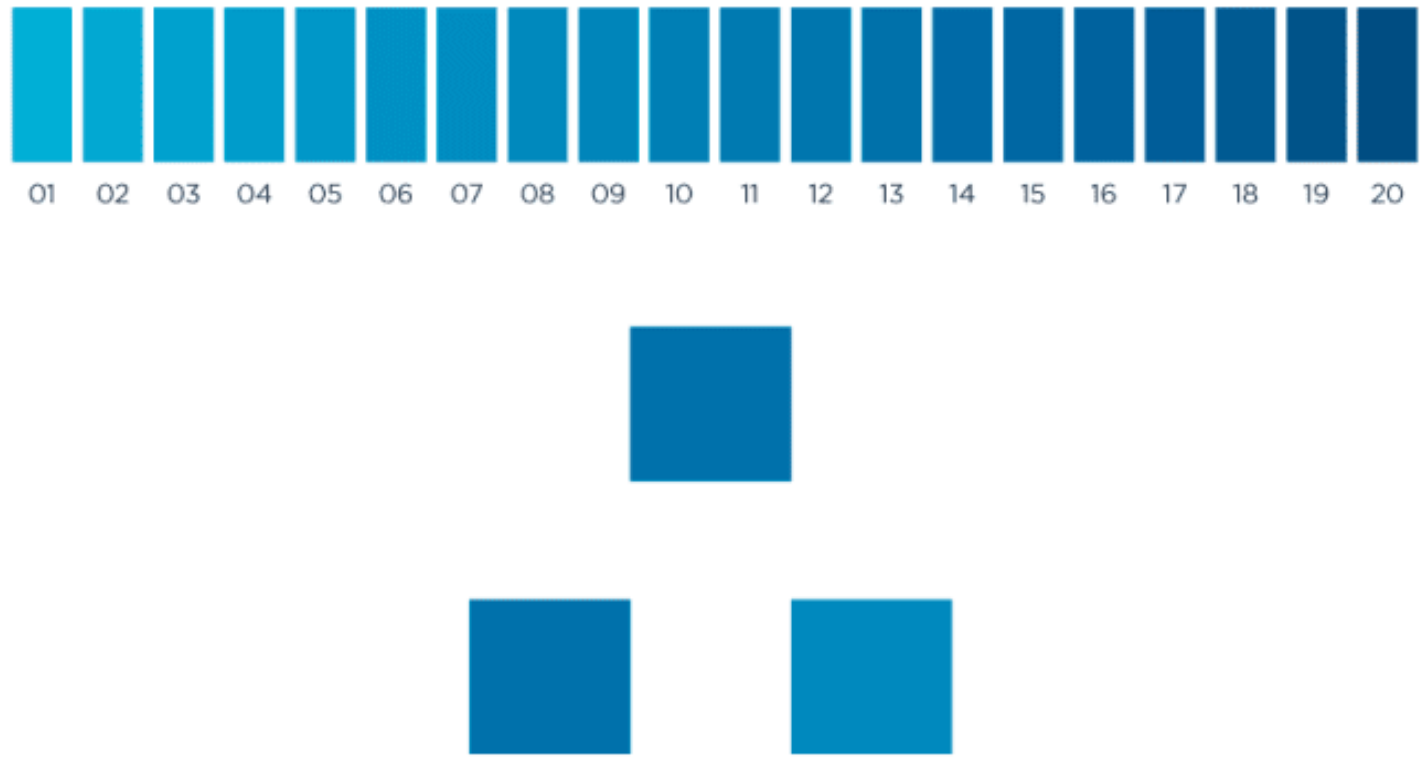

Arriba se ven los 20 tonos de azul utilizados en el estudio sobre la capacidad de distinguir colores según la lengua hablada por los participantes. Abajo de la paleta completa vemos un ejemplo de la imagen del ejercicio: los sujetos debían distinguir cuál de los dos cuadrados de abajo era idéntico al de arriba. A partir de Winawer.

Pero ¿no estábamos hablando de género? Sí, sí, a eso vamos:

Se supone que el género de una palabra (masculino/femenino) no siempre diferencia sexo. Lo hace en algunos sustantivos como señor y señora, perro y perra, carpintero y carpintera, que remiten siempre a seres animados y sexuados. Pero, en general, el género en la mayoría de las palabras no es algo que se agrega al significado, es inherente a la palabra misma y sirve para diferenciar otras cosas: diferencia tamaño en cuchillo y cuchilla, diferencia la planta del fruto en manzano y manzana, diferencia al individual del plural en leño y leña. En ese caso, se las considera palabras diferentes y no variaciones de una misma palabra. Otras veces, ni siquiera sirve para diferenciar nada porque muchas palabras tienen su forma en femenino y no existen en masculino, y viceversa. En esos casos, el género sólo sirve para saber cómo usar las otras palabras que rodean y complementan a esa palabra. Por ejemplo 'teléfono' existe sólo en masculino. No es posible decir 'teléfona', y sin embargo necesitamos ese masculino para saber decir que el teléfono es 'rojo' y no 'roja'.

O sea que el género funciona de muchas formas en castellano y no solamente como un binomio para decidir si las cosas son de nene o de nena. Pero lo que vuelve verdaderamente 
interesante el asunto, por muy gramátiques que queramos ponernos en el análisis, es que el género del castellano tiene siempre una carga sexuada, aunque remita a simples objetos. ¡No puede ser! ¿Puede ser?

\section{Sí, puede ser}

Webb Phillips y Lera Boroditsky se preguntaban si la existencia de género gramatical para los objetos, presente en idiomas como el nuestro pero no en el inglés, tenía algún efecto en la percepción de esos objetos, como si realmente tuviesen un género sexuado. Para resolverlo, diseñaron algunos experimentos con hablantes de castellano y alemán, dos lenguas que atribuyen género gramatical a los objetos, pero no siempre el mismo (o sea que el nombre de algunos objetos que son femeninos en un idioma, son masculinos en el otro). Los resultados de 5 experimentos distintos mostraron que las diferencias gramaticales pueden producir diferencias en el pensamiento.

En uno de esos experimentos buscaron poner a prueba en qué medida el hecho de que el nombre de un objeto tuviese género femenino o masculino llevaba a les hablantes a pensar en el objeto mismo como más 'femenino' o 'masculino'. Para ello les pidieron a les participantes que calificaran la similitud de ciertos objetos y animales con humanes varones y mujeres. Se eligieron siempre objetos y animales que tuvieran géneros opuestos en ambos idiomas y las pruebas fueron realizadas en inglés (un idioma con género neutro para designar objetos y animales) a fin de no sesgar el resultado. Les participantes encontraron más similitudes entre personas y objetos/animales del mismo género que entre personas y objetos/animales de género distinto en su idioma nativo.

En otro estudio de Lera Boroditsky se hizo una lista de 24 sustantivos con género inverso en castellano y alemán, que en cada idioma eran la mitad femeninos y la mitad masculinos. Se les mostraron los sustantivos, escritos en inglés, a hablantes natives de castellano y alemán, y se les preguntó sobre los primeros tres adjetivos que se les venían a la mente. Las descripciones resultaron estar bastante vinculadas con ideas asociadas al género. Por ejemplo, la palabra llave es masculina en alemán. Les hablantes de ese idioma describieron en promedio las llaves como duras, pesadas, metalizadas, útiles. En cambio, les hablantes de castellano las describieron como doradas, pequeñas, adorables, brillantes y diminutas. A la inversa, la palabra puente es femenina en alemán y les hablantes de ese idioma describieron 
los puentes como hermosos, elegantes, frágiles, bonitos, tranquilos, esbeltos. Les hablantes de castellano dijeron que eran grandes, peligrosos, fuertes, resistentes, imponentes y largos. También los resultados de María Sera y su equipo encontraron que el género gramatical de los objetos inanimados afecta las propiedades que les hablantes asocian con esos objetos. Experimentaron con hablantes de castellano y francés, dos lenguas que, aunque usualmente coinciden en el género asignado a los sustantivos, en algunos casos no lo hacen. Por ejemplo, en las palabras tenedor, auto, cama, nube o mariposa. Se les mostró a les participantes imágenes de estos objetos y se les pidió que escogieran la voz apropiada para que cobrara vida en una película, dándoles a elegir voces masculinas y femeninas para cada uno. Los experimentos mostraban que la voz elegida coincidía con el género gramatical de la palabra con la que se designa a ese objeto en el idioma hablado por le participante.

Como si todo esto fuera poco, Edward Segel y Lera Boroditsky también señalan que puede verificarse la influencia del género gramatical en la representación de ideas abstractas analizando ejemplos de personificación en el arte, en la que se da forma humana a entidades abstractas como la Muerte, la Victoria, el Pecado o el Tiempo. Analizando cientos de obras de arte de Italia, Francia, Alemania y España, encontraron que en casi el $80 \%$ de esas personificaciones, la elección de una figura masculina o femenina puede predecirse por el género gramatical de la palabra en la lengua nativa de le artista.

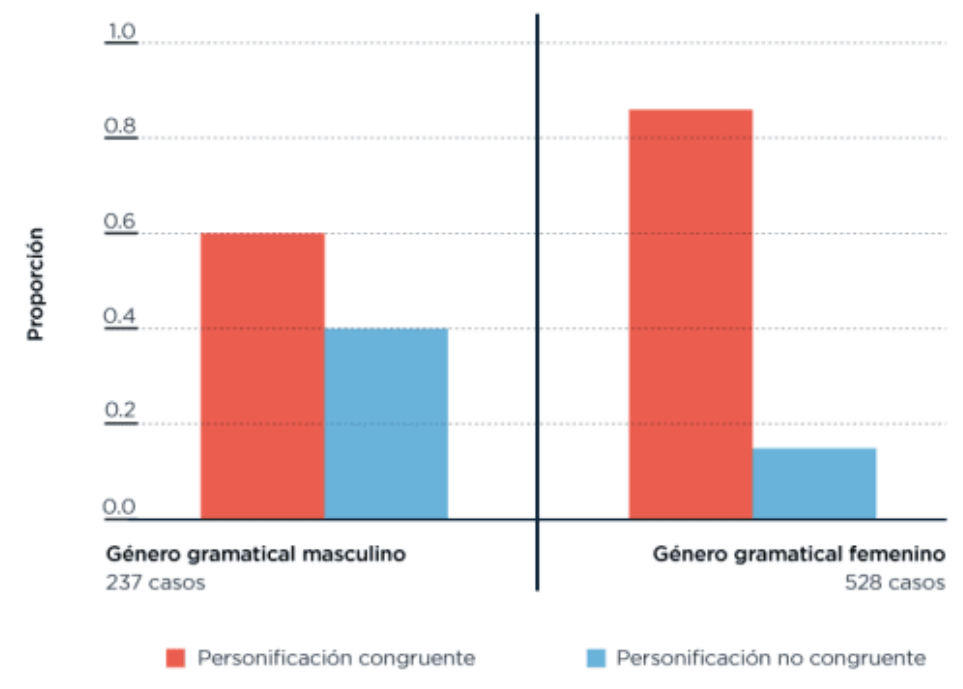

Cuando la idea abstracta personificada tenía género gramatical femenino en la lengua de le artista, fue personificado como mujer en 454 casos de un total de 528. Es decir, se produjo 


\section{Blancanieves y los siete mineros estereotípicamente masculinos}

Hasta acá todo bien: hay una relación entre pensamiento y lengua, hay una vinculación entre género y sexo en la mente de les hablantes y hay evidencia al respecto. Pero puntualmente, ¿puede la lengua tener un efecto sobre la reproducción de estereotipos sexistas y relaciones de género androcéntricas (es decir, centradas en lo masculino)?

Bueno, sí. Por ejemplo, Danielle Gaucher y Justin Friesen se preguntaron si la lengua cumple algún rol en la perpetuación de estereotipos que reproducen la división sexual del trabajo. Para responderse, analizaron el efecto del vocabulario 'generizado' empleado en materiales de reclutamiento laboral. Encontraron que los avisos utilizaban una fraseología masculina (incluyendo palabras asociadas con estereotipos masculinos, tales como líder, competitivo y dominante) en mayor medida cuando referían a ocupaciones tradicionalmente dominadas por hombres antes que en áreas dominadas por mujeres. A la vez, el vocabulario asociado al estereotipo de lo 'femenino' (como apoyo y comprensión) surgía en medidas similares de la redacción tanto de anuncios para ocupaciones dominadas por mujeres como para las dominadas por varones.

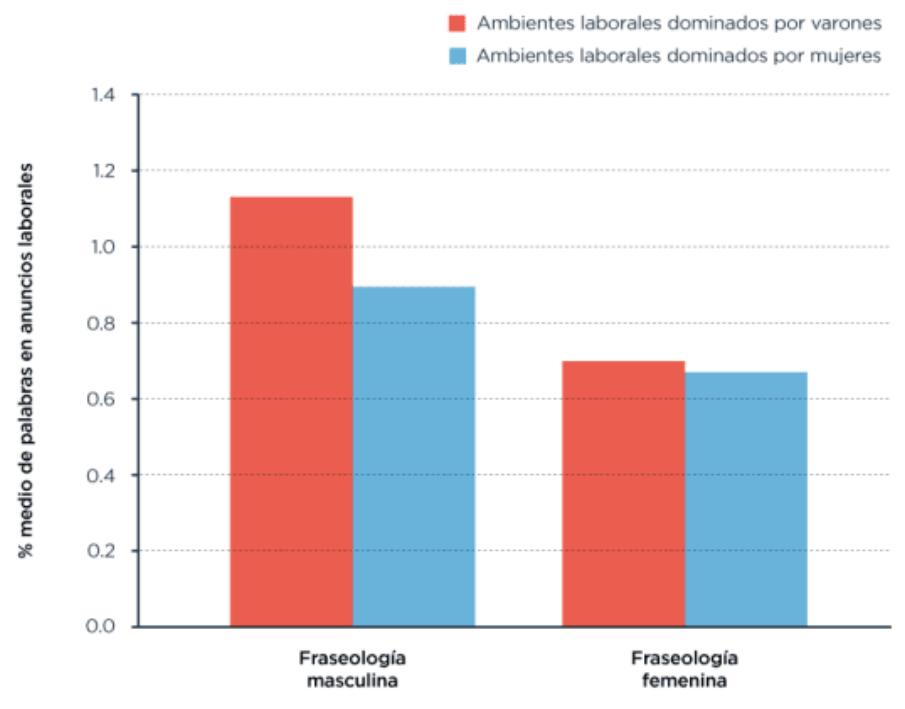

Los anuncios laborales para ocupaciones dominadas por varones contenían más palabras estereotipadamente masculinas que los anuncios para ocupaciones dominadas por mujeres. 
En cambio, no había diferencia en la presencia de palabras estereotipadamente femeninas en ambos tipos de ocupaciones.

Por otro lado encontraron que, cuando los anuncios incluían más términos masculinos que femeninos, les participantes tendían a percibir más hombres dentro de esas ocupaciones que si se usaba un vocabulario menos sesgado, independientemente del género de le participante o de si esa ocupación era tradicionalmente dominada por varones o por mujeres. Además, cuando esto ocurría, las mujeres encontraban esos trabajos menos atractivos y se interesaban menos en postularse para ellos.

El equipo de Dies Verveken realizó tres experimentos con 809 estudiantes de escuela primaria (de entre 6 y 12 años) en entornos de habla de alemán y holandés. Indagaban si las percepciones de les niñes, sobre trabajos estereotípicamente masculinos, pueden verse influidas por la forma lingüística utilizada para nombrar la ocupación. En algunas aulas presentaban las profesiones en forma de pareja (es decir, con nombre femenino y masculino: ingenieros/ingenieras, biólogos/biólogas, abogados/abogadas, etc.), en otras en forma genérica masculina (ingenieros, biólogos, abogados, etc.). Las ocupaciones presentadas eran en algunos casos estereotipadamente 'masculinas' o 'femeninas' y en otros casos neutrales. Los resultados sugirieron que las ocupaciones presentadas en forma de pareja (es decir, con título femenino y masculino) incrementaban el acceso mental a la imagen de mujeres trabajadoras en esas profesiones y fortalecían el interés de las niñas en ocupaciones estereotipadamente masculinas.

Estos son sólo algunos de los muchos estudios realizados. Si algune se quedara con ganas de más, otros estudios (como este, este, este o este) añaden evidencia sobre cómo les niñes interpretan como excluyentes los títulos de oficios o profesiones marcados por género y cómo, en general, el uso de un pronombre masculino para referirse a todes favorece la evocación de imágenes mentales desproporcionadamente masculinas. O incluso, cómo esos genéricos no tan genéricos pueden tener efectos sobre el interés y las preferencias por ciertas profesiones y puestos de trabajo entre las personas del grupo que 'no es nombrado', llevando a que puedan autoexcluirse de entornos profesionales importantes. 


\section{¿Y entonces qué hacemos?}

Es en esta línea que puede comprenderse mejor la relevancia de los esfuerzos del feminismo por introducir usos más inclusivos de la lengua. Muchos se han ensayado, empezando por la barrita para hablar de los/as afectados/as, los/as profesores/as, los/as lectores/as. Pero esta solución tiene algunos problemas. Primero, la lectura se tropieza con esas barritas que saltan a los ojos como alfileres. Por otro lado, supone que la multiplicidad de géneros del ser humano puede reducirse a un sistema binario: o sos varón, o sos mujer.

Otras soluciones fueron incluir la x (todxs) o la arroba (tod@s) en lugar de la vocal que demarca género, pero la arroba era demasiado disruptiva ya que no pertenece al abecedario y además rompe el renglón de una manera distinta al resto de los signos. La x, por otro lado, sigue utilizándose, pero al igual que la arroba, plantea un problema fonético importante ya que nadie sabe muy bien cómo debe pronunciarla. Hay quienes (por ejemplo, la escritora Gabriela Cabezón Cámara) ven en ello una ventaja: lo disruptivo, lo que incomoda, es justamente lo que atrae las miradas sobre el problema de género que ese uso de la lengua busca denunciar, es la huella de una pelea, la marca de una puesta en cuestión.

Hasta ahora, la propuesta que parece tener mejor proyección a futuro para ser incorporada sin pelearse demasiado con el sistema lingüístico es el uso de la e como vocal para señalar género neutro. Como el objetivo es dejar de referirnos a todes con palabras que sólo nombran a algunes, no necesitamos usarla para referirnos a absolutamente todo, es decir: no vamos a empezar a sentarnos en silles ni a tomarnos le colective cada mañane. Pero si estamos hablando de personas (u otres seres animades a les que les percibimos una identidad de género), nos habilita una posibilidad para hablar de manera verdaderamente inclusiva. De todos modos, esta tampoco es una solución libre de problemas: implica entre otras cosas la creación de un pronombre neutro ('elle') y de un determinante ('une'). Pero excepciones más raras se han hecho y aquí estamos todavía, comiendo almóndigas entre los murciégalos.

Algunas voces que patalean indignadas contra estas iniciativas señalan que esas propuestas 'destruyen el lenguaje'. Y no falta la apelación a la autoridad: es incorrecto porque lo dice la Real Academia Española. Pero, como le lecter ya sabe, lo que diga la Real Academia Española sobre este tema nos tiene sin cuidado. Con todo respeto. Muy lindo el diccionario. Otra de las fuertísimas resistencias a este tipo de propuestas es la de quienes sencillamente niegan que exista algún tipo de relación entre la lengua y los mayores o menores niveles de 
equidad de género. Aunque recién comentamos evidencias empíricas que sugieren que esa relación sí existe, se suele hacer referencia a la cuestión, también empírica, de que en aquellas regiones en las que se hablan lenguas menos sexuadas, por ejemplo con un genérico verdaderamente neutral, a menudo se verifica mayor inequidad de género que en otros países.

Un aporte interesante en esa línea es el trabajo de Mo'ámmer Al-Muhayir, que compara el árabe clásico, islandés y japonés, y muestra que el sexismo de la lengua no parece correlacionar con la inequidad de género. El árabe clásico utiliza el género femenino para los sustantivos en plural, sin importar el género de ese mismo sustantivo en singular. Y sin embargo, se trata de una de las lenguas más conservadoras del planeta, y en más de una de las sociedades en las que se habla (como Arabia Saudí o Marruecos), difícilmente podamos decir que hay igualdad de derechos entre hombres y mujeres. El islandés, por otra parte, es uno de los idiomas que menos cambios han sufrido a lo largo de los siglos, manteniéndose casi intacto debido a políticas de lenguaje sumamente conservadoras (no adquieren términos extranjeros sin antes traducirlos de alguna manera con raíces de palabras islandesas), y corresponde a una de las sociedades más avanzadas en cuanto al lugar que ocupa la mujer. Y el japonés directamente no tiene género gramatical, pero esta maravilla de la gramática inclusiva tiene lugar en el seno de una de las sociedades más estereotípicamente machistas que conocemos.

\section{Indice de techo de cristal}

$100=$ mejor entorno para mujeres trabajadoras

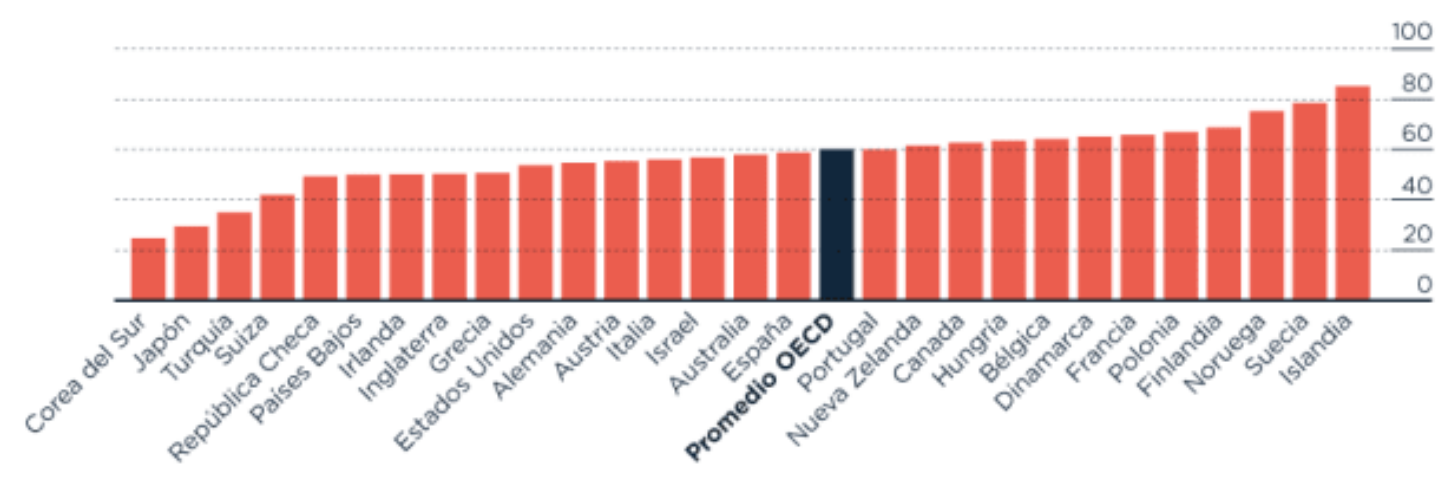

A partir de imagen de The economist, the glass ceiling index (o sea, el índice de techo de cristal, que mide equidad de género en el mercado de trabajo). 
Sin embargo, la investigación empírica aporta indicios de que los sustantivos 'neutrales' y los pronombres de lenguas sin división gramatical genérica pueden tener de todas formas un sesgo masculino encubierto. Así, aunque eviten el problema de una terminología masculina genérica, incluso los términos neutrales pueden transmitir un sesgo masculino. Esto supone, además, la desventaja de que ese sesgo no podría ser contrarrestado añadiendo deliberadamente pronombres femeninos o terminaciones femeninas, porque en esas lenguas esa forma simplemente no existe. Se dificultan entonces las iniciativas de 'subversión simbólica' de las que habla Bourdieu. Eso concluye, por ejemplo, el trabajo de Mila Engelberg a partir del análisis del finlandés, una lengua que incluye términos aparentemente neutros en cuanto al género pero que, en los hechos, connotan un sesgo masculino. $Y$ al no poseer género gramatical, no existe la posibilidad de emplear pronombres o sustantivos femeninos para enfatizar la presencia de mujeres. La autora señala que esto podría implicar que el androcentrismo en lenguas sin género puede incluso aumentar la invisibilidad léxica, semántica y conceptual de las mujeres. Algo muy similar encuentra Friederike Braun en su estudio con la lengua turca, cuya falta de género gramatical no evita que les hablantes de turco comuniquen mensajes con sesgos de género.

\section{Un hit argentino}

Por muchas guías que se hayan publicado para el uso no sexista del lenguaje, al menos cuando se trata de la lengua castellana, la cuestión no está en absoluto resuelta. Desde lingüistas hasta ciudadanes de a pie, las resistencias son diversas. Que si duele en los ojos, si entorpece el habla, si es 'correcto', si conduce a abandonar la lectura del texto y el infaltable 'es irrelevante'. Que la verdadera lucha debería centrarse en transformar 'el mundo real'. Que la lengua sólo refleja relaciones que son 'extralingüísticas'. Que modificar la lengua 'por la fuerza' sólo es una cuestión de 'corrección política' que desvía la atención del problema central y hasta lo enmascara. Pero les lecteres que hayan llegado a este punto habrán atravesado media nota escrita de forma tradicional y media nota escrita con lenguaje inclusivo, de modo que además de toda la evidencia expuesta sobre la relación entre lengua y pensamiento, podrán evaluar también cuán traumática ha sido (o no) la experiencia, y preguntarse dónde ancla verdaderamente el origen de esa resistencia, de esa desesperación por preservar intacta la lengua.

Mientras tanto, la disputa por el lenguaje continúa. $Y$ de todas las formas que puede tomar este problema, acaso la más emblemática sea el uso de falsos genéricos, es decir, términos exclusivamente masculinos o femeninos, utilizados genéricamente para representar tanto a 
hombres como a mujeres, como cuando decimos 'los científicos': técnicamente podríamos estar refiriéndonos a científiques (varones, mujeres, etc.), aunque también diríamos 'los científicos' si quisiéramos referirnos sólo a los que son varones. En cambio, sólo usaríamos 'las científicas' para hablar de las que son mujeres.

Marlis Hellinger y Hadumod Bußmann explican que la mayoría de los falsos genéricos son masculinos y que los únicos idiomas conocidos en los que el genérico es femenino están en algunas lenguas iroquesas (Seneca y Oneida), así como algunas lenguas aborígenes australianas. En castellano, incluso los sustantivos comunes en cuanto al género, como 'artista' o 'turista', que se mantienen invariables sin importar si se refieren a un varón o una mujer, acaban señalando el género de lo que nombran a partir de las otras palabras que los complementan (adjetivos, artículos, etc.). Entonces, de nuevo, para referirnos a grupos mixtos, recurrimos al género que los nombra sólo a ellos. Tal vez los únicos genéricos genuinos que tenemos sean los llamados sustantivos epicenos como, por ejemplo, 'persona' o 'individuo', que no sólo van a mantenerse invariables (no hay ni persono ni individua) sino que ni siquiera tienen la posibilidad de marcar el género en el adjetivo (porque aunque una persona sea varón, nunca será 'persona cuidadoso', ni la mujer será 'individuo cuidadosa').

Pero un poco como lo que comentábamos arriba, un genérico con sesgo machista puede suponer un problema incluso más difícil de visibilizar y 'subvertir'. Un hit argentino en este sentido es el debate por la palabra presidente:

Una nota de Patricia Kolesnikov recupera un breve diálogo en una mesa, en la cual un señor explicaba por qué está mal decir presidenta. Las razones gramaticales del señor eran inapelables: "Presidente es como cantante. Aunque parece un sustantivo es otro tipo de palabra, un participio presente, o lo que quedó de los participios presentes del latín. Una palabra que señala a quien hace la acción: quien preside, quien canta. Justamente, no tiene género. ¿Vas a decir la cantanta?” Kolesnikov cuenta que hubo un momento de duda en la mesa, hasta que la escritora Claudia Piñeiro, con sabiduría de pez que conoce el agua, respondió: “¿Y sirvienta tampoco decís? ¿O presidenta no pero sirvienta sí?”

Anécdotas como esta nos recuerdan que la lengua es maleable y que apoyar o rechazar un uso disruptivo, que tiene por objeto reclamar derechos larga e injustamente negados, es una decisión política, no lingüística. Que si se busca un mundo más igualitario, la lengua no es una clave mágica para conseguirlo, pero tampoco se lo puede negar como espacio de disputa. Y que mientras las estadísticas de femicidios crecen y el sueldo promedio de las trabajadoras 
permanece por debajo del de ellos, conviene no indignarse si alguien mancilla un poquitito las blancas paredes del lenguaje.

\section{$\underline{\text { Referencias }}$}

Language in Mind Advances in the Study of Language and Thought, editado por Dedre Gentner y Susan Goldin-Meadow

Bourdieu: La dominación masculina.

Gender Across lenguages. Acá el volumen I y acá el volumen II

Di Tullio, Ángela, Malcuori, Marisa. Gramática del español para maestros y profesores del Uruguay. Montevideo: ANEP, 2012.

Author CV/Bio Sol Minoldo: Sociologist, from Cordoba and a doctor of those who do not cure. A fan of photography and chocolate ice cream.

Author CV/Bio Juan Cruz Balian: Writer, employee and student. In that order. I don't know how to think deductively, but I can sense where things are coming from. 